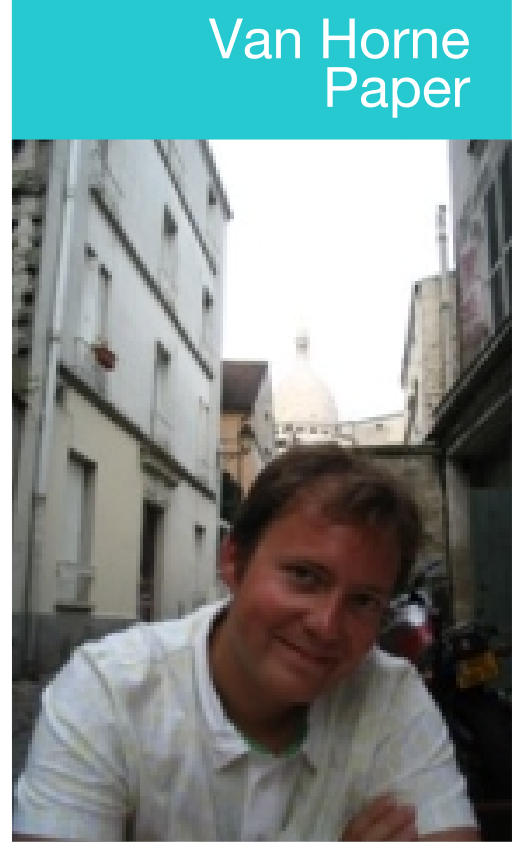

The Van Horne Institute, Canada s leading institute of public policy and education in the fields of transportation and regulatedindustries, generously sponsors an award for the best student papersubmitted to the Canadian Communication Association (CCA) annual conference in recognition of their mandate to consider "transportation" in its broadest context, including media and telecommunications. For more information on the prize, including how to apply, please refer to the cCA web page (www.acc-cca.ca/ files/Van\%20Horne.pdf).

This year s prize was awarded to Rob McMahon, a second year PhD student at the School of Communication, Simon Fraser University. Drawing on a critical public sphere perspective, he is particularly interested in exploring forms of "mainstream" journalism practice and news values that might promote democratic, inclusive intercultural news coverage. Mr. McMahon s Van Horne Prize paper explores these issues with a particular focus on Aboriginal media coverage.

The CCA and Stream congratulate Mr. McMahon for receiving this richly deserved prize.

\section{Bringing Peace to Practice? The Need to Consider Journalism Practice When Reforming Aboriginal Media Coverage in Canada}

\section{Rob McMahon}

Trials in a courtroom have the inevitable downside of producing winners and losers.

My hope is that this judgment will shine new light on the path of reconciliation that lies ahead.

Justice David Vickers ${ }^{1}$

In a non-binding decision concerning the Xeni Gwet' in First Nations' aboriginal ${ }^{2}$ title to a large portion of their traditional territory, Justice David Vickers advised the Crown and the First Nations group to negotiate a settlement that explicitly avoided assigning blame on either of the two parties. He called for the need for both parties to avoid splitting themselves into "winners" and "losers," a dichotomy that the judicial system tends to promote, but one that also hardens divisions and so undermines attempts at long-term reconciliation.

In this paper, I argue that in their daily practice of news production, media professionals should consider approaching disputes between Aboriginal and non-Aboriginal groups in the same way. Justice Vickers points out that court cases frame conflicts as "struggles" or "battles" between "winners" and "losers"; likewise, so do many newspaper stories. Articles written about the Xeni Gwet'in trial tended to summarize the key facts of the case - including assigning the positions of "winners and losers." By recreating the dichotomy that is created through reporting conflict, the news articles inadvertently perpetuated the disagreement they reported. Although in the example noted above, The Globe and Mail did a good job in repeating Justice Vickers's statement, (and therefore repeating his admonishment to consider reconciliation rather than conflict), not all media outlets are as prudent. Therefore, given the level of coverage that newspapers devote to long-standing debates between Aboriginal and non-Aboriginal groups in Canada, to support rather than undermine Canadian society's attempts at 
reconciliation, news producers should develop more appropriate reporting methods - in short, they must reform their daily practices.

I begin this essay by demonstrating that much of the coverage of First Nations groups in Canada perpetuates representations of conflict between Aboriginal and non-Aboriginal Canadians. Beyond winners and losers in court, during dramatic events such as protests or standoffs, portrayals of Aboriginal groups are similar to those that appear in wartime news correspondence. Conflict between Aboriginal parties and the state is portrayed as a struggle between enemies, and First Nations groups are framed as being located outside of, and in opposition to, the Canadian nation-state.

Next, I argue that to improve this situation, alongside other changes such as improved hiring practices and diversity training, the routines of daily journalism must also be reformed. Recent developments in journalism studies identify the (limited) ability of journalists to act as agents as a way to consider and change their roles as news producers. I argue that it is important to focus attention and action on this daily practice. After noting recent work that validates the ability of journalists-as-agents to enact this change, I turn to the nascent field of Peace Journalism as one approach to practical reform, arguing for the need for media scholars to consider its applicability to local conflicts that do not involve overt violence (i.e., coverage of Aboriginal issues in Canada). I end by briefly identifying a few examples of journalism practice that are sites of reform which might benefit from suggestions offered by Peace Journalism.

\section{Creating the Dichotomy: Aboriginal Journalism as War Journalism} Newspaper coverage portrays groups in conflict with one another, and this is a fundamental tenet of journalism. Studies have long shown that journalists draw on and emphasize dramatic events and overt conflicts when writing their stories. As Herbert Gans (1979) writes in Deciding What's News, "because the news is dominated by stories about conflict, and because of its concern with unity and consensus, or the lack thereof, the overall picture is of a conflicted nation and society" (p. 22, emphasis added). More recently, Ida Schultz (2007) identified conflict as one of the main criteria journalists and editors use to define an event as newsworthy, writing: "When the news criterion of conflict is used in the daily construction of newsworthiness, this means selecting stories and angles accentuating conflicts of interest between people, between causes, organizations, etc.” (p. 197).

Of course, this kind of representation is not created by the media alone. Conflicts between groups do exist in "material” reality. A range of institutions 
frame relationships between parties in terms of conflict. For example, the court system resolves conflicts through assigning blame and defining winners and losers. The prominence of such representations in newspapers is also part of well-crafted media strategies designed by groups or individuals in society to draw attention to specific political issues. To catch the media's attention, these parties employ "pseudo-events" that illustrate an intangible issue using a concrete situation performed for the benefit of the media's cameras or story requirements (see Boorstin, 1961; Dayan \& Katz, 1971). For example, First Nations stage “standoff” protests and the RCMP host press conferences.

Perhaps the clearest example of news coverage that focuses on overt conflict between clearly delineated parties is during war. Newspapers clearly represent to their audiences that the parties involved in the story are in direct conflict with one another. The stories are organized around specific events, like battles, noting for audiences which side "won" and which side "lost."

But embedded in portrayals of direct warfare are more indirect methods of distinguishing between involved parties. These symbolic techniques use images or language to rally support (or build condemnation) among noncombatants. In this sense, during wars (at least international wars), the media also becomes an agent of the ethnocentric values evoked by the language or imagery used to describe the actions of “foreign enemies.” Gans's (1979) study of news values notes, "the clearest expression of ethnocentrism, in all countries, appears in war news” (p. 42). While his study uses the example of US news coverage during the Vietnam War which depicted the North Vietnamese as the clear enemies of the American public, a similar analysis could apply to coverage of many other international conflicts.

Key to the argument linking ethnocentrism and war reportage is the idea that "enemies" are externalized and defined as separate from and in opposition to the individuals comprising a newspaper's audience. In Gans's example, national news magazines and television shows consistently portrayed the North Vietnamese as enemies of their audience, the American public. In contemporary conflicts such as the "War on Terror," "terrorists" are portrayed as external from and in opposition to the media's assumed audience. Quoting Pierre Bourdieu, Ida Schultz (2007) points out that, "the journalistic field is part of the field of power, not least because the constant cultural production of social discourse not only implies production of categories for 'vision' of the social world, but at the same time, categories of 'division'” (p. 192).

Before moving on, I must consider one key presupposition underlying my argument: the ideal of a pluralistic society in which mass media

4 - Stream: Culture/Politics/Technology 1(2) 
institutions play a key role in mediating social and political conflict. In this sense, news media mediates between a variety of perspectives and values held by different groups. As Manuel Castells (2000) argues in his theory of "network society": "Power relations are by nature conflictive, as societies are diverse and contradictory. Therefore, the relationship between technology, communication, and power reflects opposing values and interests, and engages a plurality of social groups in conflict” (p. 239).

When these conflicts arise, in a perfect world, the news media act as a forum for open discussion. The assumption is that all involved and affected groups are and should be included within the political and public discourse. As Castells writes, "the media are not the holders of power, but they constitute by and large the space where power is decided” (p. 242).

Implicit in this line of reasoning is the assumption that journalism has an impact as a political force in society. Pierre Bourdieu (1998) argues that "journalists ... owe their importance in society to their de facto monopoly on the large-scale informational instruments of production and diffusion of information. Through these, they control the access ... to what is sometimes called 'public space'” (pp. 329-30). In this conception of the role of journalism, all speakers should have the right to equal access to public space "in which only the "force of the better argument prevails" (Salter, 2005, p. 94). The idealized role of journalists is to facilitate public communication.

Critical media scholars have long problematized this assumption, demonstrating how external factors, organizational constraints and a range of other variables influence the media's ability to act as a "neutral” mediator between parties. Research has found that the news media implicitly fail to adequately represent the views of all groups within society, and by doing this, fail to allow these groups to participate equally in political life. However, this paper argues from the position that one of the goals of media reform is to work with practitioners to achieve this situation as much as is possible.

Bringing the argument back to the discussion linking wartime coverage to ethnocentrism, research has uncovered a similar dynamic played out in coverage of ethnic minorities in Canada. A long tradition of media analysis has identified the "us against them" dichotomy as a key problem within mainstream media coverage of minorities. Karim Karim (1993) argues that certain cultural discourses seem to operate in hegemonic manners that "strongly influence public perceptions of whether particular individuals should be considered members of 'in' or 'out' groups” (p. 197). Ethnic minorities are represented as being in opposition to, as opposed to part of, Canadian society. As Karim argues, "It is in the shifting meanings of words 
that are used to describe Canada and its population that we can see how symbolic constructions, deconstructions, and reconstructions serve to include or exclude specific types of people” (p. 197).

This kind of situation is echoed in coverage of Aboriginal groups in Canada. The 1996 Royal Commission on Aboriginal Peoples highlighted a key failure of the media: its tendency to dichotomize Aboriginal people as separate, and in opposition to, the Canadian nation. It noted the media "created images of Native people that invoke fear and hostility among the public during serious disputes over land and resources” (as cited in Lambertus, 2004, p. 5).

Several studies that employ content analyses of media coverage go further, explicitly linking overtly "war-like" symbols and language to representations of conflicts between Aboriginal parties and the state (see Lambertus, 2004; Alia, 1999; Roth, 2005). Two well-researched examples come from coverage of the confrontations at Oka/Kanehsatake and at Gustafsen Lake. Both events received a large amount of press coverage that persistently characterized them as "warlike." A content analysis of the Montreal Gazette's coverage during the 1990 Oka crisis conducted by Marc Grenier found the newspaper was "literally obsessed with conflict-based Indian issues during the sample period, with conflict orientations present in $80 \%$ of all Native Indian straight [i.e. hard] news stories" (as cited in Lambertus, 2004, p. 11). Similarly, when Sandra Lambertus (2004) examined content analyses of several conflicts that First Nations have been involved in since the 1995 Gustafsen Lake standoff, she discovered the media often used wartime characterizations to define the events. Her list of examples of images of Aboriginal parties used by the media included photographs of protestors wearing camouflaged clothing, Emergency Response Team personnel dressed in flak jackets and carrying high-powered weapons, and, at one point, a convoy of armoured personnel carriers driving along a dusty forest road (p. 4).

It is generally acknowledged that Aboriginal Canadians are victims of the legacy of colonialism in Canada. By perpetuating the dichotomy of "Canada" vs. "Aboriginals," war-themed media coverage precludes attempts at reconciliation between these parties. Despite work being done to achieve reconciliation in Canada's law courts, classrooms, and neighbourhoods, the 1996 Royal Commission found the media's characterizations tend to distract audiences from the contextual issues surrounding disputes, in turn contributing to misperceptions about Native Peoples. When members of the Canadian public who rely on the mass media for information on First Nations base their understandings on war-like dichotomies, they are more likely to

6 - Stream: Culture/Politics/Technology 1(2) 
come to negative conclusions. As Lambertus found, without a nuanced understanding of conflicts between Aboriginal and non-Aboriginal groups, the public "will be less open to considering any Native protest as a valid demonstration by valued Canadian citizens” (pp. 200-201).

Given the widespread problems stemming from such coverage, any attempt to improve newspaper coverage of Aboriginal issues in Canada must address the factors that create and perpetuate this dichotomy between "Aboriginal” and "non-Aboriginal” Canada.

\section{Journalistic Practice as a Site of Reform}

In the past decade, newspapers have demonstrated an increasing desire to improve representations of Aboriginal groups. In the United States, the 2007 "Reading Red Report” performed content analysis of 1,741 articles from 10 mainstream newspapers, and found that in the best stories, "local Native Americans were profiled as everyday people doing positive and negative deeds” (Reading Red, 2007, p. 37, emphasis added). The Report argued this improvement may be due to the increasing political significance of Native Americans - a situation that could also be applied to Canada, which has seen a similar rise in the political power of Aboriginal groups. In other steps towards improvement, Canadian media outlets have been involved in wellpublicized activities to improve coverage of diverse communities, hire more Aboriginal journalists, and regularly engage in relationship-building activities and training sessions to achieve these goals.

Yet despite these attempts at reform, problems remain. While actions such as hiring a more diverse and representative base of journalists or engaging in diversity training are important, such solutions ignore the structural factors present in everyday journalism that contribute to problematic coverage.

Reform designed to improve problematic coverage of Aboriginal communities in Canada must also consider daily journalism practice: the "nuts and bolts" of the trade. Embedded within the process that journalists use to develop their news stories are practices and assumptions (in Bourdieu's terms, doxa and habitus) that inadvertently frame events as conflicts and Aboriginal groups as enemies. It is only by examining the processes that generate these representations that solutions can be found: in essence, one must examine the means, along with the ends, of problematic coverage. 
Consider stereotyping as an example of one such effect of journalism practice on media representation. In his work examining the historical preponderance of stereotypes of Aboriginal people in the Canadian news, Robert Harding found negative images of Aboriginals repeated throughout history. He argues that journalistic practice is a key reason such representations are so prevalent throughout history. Simply put, stereotypes make a reporter's job easier. As he writes:

By invoking stereotypes, journalists avail themselves of a ready-made structure that they can hang their stories on ... Journalists do not derive their stereotypes based on actual contact with those people who are the object of them, but rather from their stereotypical ideas based on a wide variety of indirect sources, including their immediate work and social circles, and from premises that filter through the organizational hierarchy. (Harding, 2005, p. 325)

Harding thus links a reliance on stereotypes to journalistic practices. Harding's conclusion is backed up in an article by Minelle Mahtani, who outlined that "the use of a particular narrative structure, the reliance on the government for stories and sources, and the need to create conflict all contribute toward the stereotyping of visible minorities in Canadian news media” (Mahtani, 2001, ๆ 45). Along with stereotyping, problems with cultural understanding during newsgathering activities also demonstrate how daily practice can influence media representations. Lambertus found that "journalists who lacked an understanding and an appreciation of Native cultural traditions were more susceptible to sensationalizing unfamiliar religious practices, making simplistic inferences, and insensitively representing Native traditions” (2004, p. 194). As such, she points to the need for media personnel to become aware of their latent tendency (as demonstrated in their daily practice) to create the dichotomies that result in an "us against them" framework.

After interviewing Northern Aboriginal leaders, Valerie Alia (1999) identified a similar situation. Along with ethnocentric beliefs and a lack of knowledge of Aboriginal political priorities, traditions and values, the Aboriginal leaders pointed out how journalists' fears of traveling to remote communities and more general fears of Aboriginal people are projected to news consumers (pp. 32-33). As she writes:

I had heard that non-Aboriginal journalists were afraid to go into Aboriginal communities first-hand, a fear derived from stereotypes that were often perpetuated by the news media

8 - Stream: Culture/Politics/Technology 1(2) 
themselves ... Yet my experiences in these communities were both positive and crucial to the accuracy of my understanding of people and issues, as a researcher and a journalist. (p. 54)

This situation also involves organizational factors within newsrooms. For example, Lambertus (2004) found that one print reporter in her research sample, who was allowed into the Aboriginal protestors' camp, felt constrained by the editorial practices of his outlet, explaining that "you were really limited in what you could do ... The editors were going for the drama, they weren't going for the philosophical” (pp. 59-60).

Rather than reform journalistic practice, media outlets have focused on "putting the cart before the horse": educating journalists on cultural issues through diversity training or hiring more Aboriginal reporters. These reforms, while commendable, ignore any consideration of the daily practice of journalism, as situated inside and constrained by a particular organizational structure. I argue that until the underlying structure of media production specifically the proclivity of journalists to employ "war-like” images and conflict-based story structures when writing about Aboriginal people - are changed, problems will remain.

Therefore, any strategy of media reform aiming to improve coverage of Aboriginal issues must consider the agency of journalists, while recognizing they are embedded within the structures of news organizations and society at large. It must examine the question of whether journalists even have the ability to change their daily practice. In short, such an approach must consider the long-standing debate between structure and agency in journalism.

\section{Structure/Agency in Journalism}

Research has long proven that journalists are not free to report on events in an unrestrained fashion. Shoemaker and Reese's Mediating the Message (1991) outlines a number of factors that influence the way the news is produced. These factors include individually oriented constraints such as personal biases, as well as a number of external factors, from society's ideological stance to the influence of commercial advertisers. As Robert Hackett (2007) points out, while journalism “operates within a nexus of sometimes contradictory forces that may allow scope for agency and alternative practices ... those spaces are limited, constrained by powerful forces both within and outside the media field” (p. 5). 
Building on these developments, political economists have noted the potential for a theoretical model of news production that takes these structurally deterministic factors into consideration, but also identifies the spaces in which journalists can exercise agency. In an article entitled "Culture, Communications and Political Economy," Peter Golding and Graham Murdock (1996) link the construction of social meaning to both the constraints of institutional structures and the activities of individual agents. They note that critical analysis must consider questions of agency and structure, and discern the constraints that shape the actors in the real world. They call for a "critical political economy" that examines not only the structures of ownership and advertising, but also the consequences of journalistic practice, journalistic recruitment, and the professional ideologies of news structures. As they put it, "the autonomy of those who work within the media is a matter of substantial interest to political economists [whose] aim is to discover how far this autonomy can be exercised” (p. 23). This recognition of "agency within structure" is also discussed by Manuel Castells (2000) in his concept of the "network society":

Meaning is constantly produced and reproduced through symbolic interaction between actors framed by this social structure, and, at the same time, acting to change it or to reproduce it ... There is no systemic dominance in this matrix of relationships ... Meaning is produced, reproduced and fought over in all layers of social structure. (p. 7)

Media scholars are now mapping the spaces in which journalists can act. Pierre Bourdieu, a key proponent of the "agency in structure” model, argued "journalists will be able to position themselves to a certain extent but always within the structures of the social space which surrounds [them]" (quoted in Schultz, 2007, p. 193). Bourdieu identified this "field of media production" as a site of struggle, and noted it includes the organizational routines and professional practices that journalists engage with on a daily basis. As Schultz (2007) points out:

Journalistic habitus thus implies understanding the journalistic game, and being able to master the rules of that same game ... In this way we can assume that there will be different positions in the field and that journalistic autonomy will depend on this. (pp. 193-194)

Writing about the production process of television news, Bourdieu (1998) noted the importance of considering both the position of journalists within media organizations and the wider networks they are enmeshed in during 
their daily routines. In an article exploring the possibility of agency within the field of journalism, Hackett (2006) pointed out that the most important forms of structural influence on journalism are the indirect, long-term restructuring of professional routines. As a specific professional hierarchy, a news organization is replete with power relations that may be "manifested or even constituted within the everyday routines and ethos of workaday journalism” (p. 7).

By understanding the relationships between and inside these two areas of influence, Bourdieu (1998) argues that one gains the ability to reform journalistic practice, and concurrently, the media product that is the result of such practice:

Journalists who might initially feel attacked will feel that, by spelling out things they know vaguely but don't really want to know too much about, I am giving them instruments of freedom with which to master the mechanisms I discuss ... If people became aware of them, conscious actions aimed at controlling the structural mechanisms that engender moral failure would be possible. (p. 335)

Put differently, Schultz (2007) notes that transforming journalistic doxa from a set of "implicit, tacit presuppositions in the journalistic field" into an explicit form helps media workers consider those practical activities they generally take for granted (p. 194).

In all of these theories, journalists are not treated as occupying and mindlessly obeying the routines and practices as defined by their roles in a news organization or as members of society, but rather are engaged in daily struggles over defining the boundaries and specific activities associated with these roles. As media ethnographer Mark Allen Peterson (2003) notes, the field of news production is "always a site of struggle over what the meaning of the text is to be ... [and journalists use] various degrees of resistance, cynicism, or acquiescence” to exercise their agency within an organizational structure (pp. 179-182).

However, despite this growing awareness of the need to situate structural reform of media organizations in a critical examination of the field of media production, many researchers concerned with ethnic media in Canada - or media in general - still fail to acknowledge the practice of journalism as a focus of study. Ida Schultz (2007) argues that while news ethnography is recognized as a key method in the study of news production, "we need more research on the everyday processes of news work in different 
cultural settings in order to understand the diverse, globalized journalistic cultures of the 21st century" (p. 191). Instead, Schultz writes, past studies of the sociology of news production have focused on political economy, the social organization of news, or cultural practices related to newsgathering. In terms of Aboriginal coverage in Canada, as Lambertus (2004) writes in her study of news coverage during the Gustafsen Lake standoff:

Findings tend to characterize media as either entirely responsible for media representations or having little or no agency against political and commercial entities that influence media characterizations ... Any proposed explanations ignore the complexity of the circumstances and the lived experiences of the news producers that may be at play. (p. 181)

However, researchers concerned with issues of media representation of ethnic minorities in Canada appear to be situating their research in the field of journalistic practice. Though she noted the dearth of research in the area at present, in her comprehensive survey of the field of ethnic media research, Mahtani interviewed a number of media researchers and found that above all, these individuals insisted on the importance of situating analyses with the organizational and behavioural practices that take place within the media's field of production (2001). These researchers noted it is important to "understand the mechanisms through which distorted and stereotypical representations are produced” (\ 66).

Uncovering and reforming the journalistic practices that lead to misrepresentations of Aboriginal issues in the mass media can help formulate practical solutions to problems media outlets have demonstrated they are interested in committing resources to solve. But now that this has been established, what specific aspects of the practices of news production must be reformed?

\section{Searching for Solutions}

Peace Journalism at Home?

The notion of "Peace Journalism" is one recently proposed theoretical approach that is grounded in an examination of the process of media production and which focuses on empowering journalists to fulfill the media's mandate to act as an effective mediator between groups. Peace Journalism involves a critical examination of journalism practices and is conscious of the tendency of certain media representations to perpetuate 
conflict and war. While Peace Journalism research has thus far focused on narrowly defined "war" conflicts in areas like the former Yugoslavia, Ireland and Israel, it may be a viable solution to help improve journalistic coverage of Aboriginal issues in Canada.

As defined by proponents Jake Lynch and Annabel McGoldrick (2005), "War" (as opposed to "Peace") Journalism portrays conflict as a struggle between political actors. Traditionally structured War Journalism articles portray conflict so that an inch gained by one side is an inch lost by the other. In War Journalism, solutions only come about when a clear winner and a clear loser are identified. Thus, even when compromise is reached, one party is assumed and portrayed as having received a "better deal" than the other. As Lynch (2002) describes it, "the classic journalist's portrayal of conflict is as a titanic tug-of-war, a zero-sum game between two parties, played out along a single axis and consisting entirely of violent exchanges” (pp. 2-3).

Peace Journalism aims to apply principles of conflict analysis in order to reform the daily practices journalists use to portray conflict in the media. Instead of a tug-of-war between two dichotomized parties, Peace Journalism aims to frame conflict "as a round table, consisting of many parties ... [and] a complex, interlocking pattern of fears, inequalities and resentments which can only be overcome by seeking, devising and implementing complex, interlocking solutions” (Lynch, 2002, p. 3). The goal of such a technique is to remove the emphasis on blaming specific parties and instead examine "the structural/cultural factors which perpetuate the conditions for violence" (p. 3). Peace Journalism calls on journalists to "distinguish stated demands from underlying needs and objectives, to access voices working for creative and non-violent solutions, and to keep eyes open for ways of transforming and transcending the hardened lines of conflict” (Hackett, 2007, p. 4).

Thus, Peace Journalism re-envisions the two-part dichotomy present in most coverage of conflict as a "cat's cradle" of relationships between a variety of stakeholders. In this sense it employs a similar approach as is called for in political and judicial decisions involving Aboriginal groups in Canada, such as treaty negotiations or land claims. ${ }^{3}$

With Peace Journalism as a possible framework in which to situate reforms of journalistic practice involving Aboriginal issues, I next identify two specific areas that might benefit from such consideration: the "internal" and "external" dynamics of media production. For the purposes of this paper, consider the internal dynamics of media production those factors intrinsic to the news organization or the journalist herself or himself, such as the cultural or personal biases of individual journalists and organizational politics. The 
external dynamics are those factors external to individual news organizations or journalists, and include examples such as the ability of sources to influence news coverage. While a comprehensive catalogue and discussion of these practices must be developed, given the scope of this paper I will briefly explore these initial examples.

Sites of Internal Reform: Journalistic Objectivity

Of the internal factors affecting the daily practice of journalists that must be considered in a Peace Journalism framework, one is the issue of bias and objectivity. While biases can be intentional or unintentional, with regards to new media, the term "bias" generally describes the distortion of information causally connected to a journalist's values, including "irrationality, illusion, prejudice, greed, ambition, and religious fervor” (Klaidman and Beauchamp, 1987, p. 60). Media commentators who perceive a conscious attempt to skew the "truth" about an issue in media label a particular publication or reporter as "biased," questioning the value and the reliability of the news. In a recent study examining the Canadian public's views towards media coverage, the Canadian Media Research Consortium (2004) found that two-thirds of Canadians believe news in Canada is not often fair and balanced - and that this perception is growing, with 59 per cent of people polled stating maintaining fairness and balance in the news has become a bigger problem in recent years.

It is impossible for journalists to completely avoid bias. When engaging in media production, journalists make sense of what is going on in terms of the signifying repertoire available to them. Reporters are embedded within the dominant cultures in which they operate. It follows that research from a variety of disciplines, from cultural anthropology to psychology, that have "taken great pains to demonstrate that human beings are cultural animals who know and see and hear the world through socially constructed filters" (Schudson, 1978, p. 6). So-called "bias" is now generally understood to be an embedded aspect of human nature.

Following this, a number of journalism scholars concerned with issues of bias and objectivity argue that effective media production practices can help mitigate these problems. As Stephen Ward (2004) argues, rather than perceiving the journalist as "a passive recorder who aspires to be a perfect recording instrument," through daily practice, a journalist can work to "reform and improve his or her schemes of understanding” (pp. 262-264). Such an approach calls for reporters to use procedures that compare and contrast different perspectives on a single issue to arrive at a clearer approximation of "truth." Given that every story contains multiple facets, journalists should attempt to draw together various facts, contexts, and

14 - Stream: Culture/Politics/Technology 1(2) 
perspectives, and represent as many of them as possible. In this sense, by reforming media routines, journalists will have a tool with which to mitigate the unconscious impacts that personal biases bring to their work. Put in the context of cross-cultural disputes, as discussed earlier, a journalist with a limited understanding of the nuances of a specific cultural practice, or the historical context of a dispute, is more likely to fit the facts into a simplistic dichotomy. This distortion is created through cultural assumptions that are due to "gaps in historical knowledge, reliable cultural information, or personal experience” (Klaidman and Beauchamp, 1987, p. 74). By offering procedures as “tools," practical-focused reforms such as Peace Journalism can help journalists overcome these cross-cultural misunderstandings.

Placed in the Peace Journalism framework, such an approach can also help journalists improve their understanding of the larger structural factors that lead to conflict, rather than focusing on pinning blame at a personal level. As Lynch and McGoldrick (2005) argue, to be successful in promoting accurate and effective representations between parties, journalism must access a variety of perspectives and portray events as linked to contextual factors that may perpetuate violence (or block compromise). As well, by reforming their everyday practices in a way that overcomes cultural bias, journalists can avoid the tendency to over-emphasize conflict and incorrectly interpret events according to their own internal biases (and thus perpetuating a conflict-based frame in their coverage). Such efforts can be linked to cultural diversity training programs for journalists. As Alia (1999) writes, “changing the media means changing the journalists' attitudes and knowledge base, a process requiring what might be called cross-cultural literacy” (p. 44).

\section{Sites of External Reform: Dealing with Sources}

Along with assisting journalists to overcome internal influences on their daily practice, a comprehensive reform of journalism practice must consider external factors. One example of an external influence is the way journalists approach and select the sources they rely on when gathering information for their stories. A revised form of journalistic practice that avoids misrepresenting or limiting sources could help address some of the problems of coverage of Aboriginal issues in Canada.

Beginning in World War I and continuing with the large-scale public relations campaigns that have become prevalent, Michael Schudson (1978) traces the growing belief among journalists that "the world they reported was one that interested parties had constructed for them to report" (p. 6). Schudson's work notes that journalists face a complex, highly organized environment when considering how to collect the information they use to construct their stories. 
Compounding this problem is pressure placed on journalists by their editors, and others in the organizational hierarchy, who assume that for a story to be credible it must "bear the stamp" of certain sources. This highlights the control that editors have over the sources contacted by journalists. As Gans (1979) found:

Journalists do apply news judgment, both as members of a profession and as individuals, but they are by no means totally free agents, and in any case, they rarely make selection decisions on overtly ideological grounds; rather, they work within organizations which provide them with only a limited amount of leeway in selection decisions, which is further reduced by their allegiance to professionally shared values. (p. 79)

Since journalists, especially those covering "breaking news," are rarely at the scene of an event, their work consists of collecting and evaluating others' interpretations. As Pedalty (1995) found, especially in conflict situations that involve fast-breaking, unpredictable events, journalists are usually evaluating second- and third-hand reports, and therefore must "comb through complex layers of interpretation and representation, hoping to derive a more concretized sense of the original event” (p. 125).

Therefore, access to sources is a key structural challenge faced by journalists, especially in a conflict environment - and in such an environment certain groups more often and more readily convey information. Research has shown that in conflict situations, authorities like the military and state police systems are key sources that also often engage in activities that control or restrict the flow of information to journalists. Referring to a recent study conducted by NewsWatch Canada of press coverage of the Afghanistan and Isreal/Hezbollah wars, Hackett (2004) noted that "as [Peace Journalism] theory predicts, military, official and political elite sources predominate over ordinary civilians” (p. 4). Pedalty (1995) found that the United States embassy in El Salvador was relied on as a source for most issues covered by foreign correspondents during the Salvadoran Civil War from 1980 to 1992. As he writes, "most editors demand that news stories include the perspectives, or at least the quoted statements, of official US government sources” (p. 70).

By influencing access to information in this way, certain "authoritative" sources (primary definers, in Stuart Hall's term) can help to frame a story in their preferred manner. As Peterson (2003) writes, 
By controlling what counts as valuable, dominant social agents can induce others to struggle over rewards within a system that already favors their position. Once established, such a dominant position becomes orthodox; it is the system of values according to which people measure their own success and competence, and against which people rebel. (p. 178)

This kind of situation has played out in coverage of Aboriginal conflict in Canada. A number of commentators have written about media coverage of the "Oka crisis" of 1990, pointing to evidence that suggests "some media organizations were too close to government sources to be objective about the events at Oka” (Harding, 2005, p. 313). Harding (2005) cites a study that found that "news outlets had a cozy relationship with the government and were 'instrumental in accomplishing the government goal of public opinion management”' (p. 313). In Lambertus’s (2004) study, journalists worked to "maintain a positive rapport with important media sources" like the RCMP (p. 26). Therefore, in situations that involve conflict between Aboriginal and nonAboriginal groups, journalists are in danger of foregrounding one party's representation of a conflict to the detriment of others. By failing to contact Aboriginal sources, journalists “shut out” their voices. The 1996 Royal Commission on Aboriginal Peoples came to this conclusion, noting that Aboriginal people are often excluded from the media, and their voices are routinely misappropriated by non-Aboriginal people (quoted in Harding, 2005). While this situation appears to be improving, further research is needed to confirm that this is true.

Generally, journalists who are heavily influenced by elite sources tend to portray a situation as an isolated conflict between parties, rather than the result of long-term structural forces. However, while Lynch acknowledges that the journalistic goal of achieving "balance" is attained through sourcing comments from each side of a conflict, he suggests that "selections from their various spokespersons' comments attempt to define positions on the attack, rather than by searching for common ground” (Lynch, 2002, p. 10). Instead, much like Lambertus's conclusions, they point out the need for a more inclusive, less conflict-based representation of source comments and overall story context.

Given that conflicts such as standoffs or protests are the culmination of long-term structural factors (such as the legacy of colonization and rules imposed by the Indian Act) rather than short term, event-driven disagreements, it is safe to assume the Aboriginal group's point of view would highlight such factors. 
As Gans (1979) found, source selection is one practice in which journalists can exercise agency. He wrote that "contact with sources, powerful or not, is almost entirely left to reporters” (pp. 119-120). For example, Lambertus (2004) found that early in the Gustafsen Lake conflict, Vancouver Sun stories began challenging the police perspective of the event, by including "greater contextual information about the dynamics between the police and the media and the interactions between police and various sources” (p. 4). She argues:

Some journalists, however, did not confine themselves to Sergeant Montague as the only RCMP source. They developed informal channels to get insider information ... Informal sources never became major influences in the news accounts, but the details provided were helpful to the media during the question period of the press conferences. (pp. 68-69)

Ending on a positive note, Lambertus notes that her case study's findings support efforts of news media to reform their practices in such a way as to "allow journalists to emerge as active players in the event that they are reporting” (p. 195). While she acknowledges this shift would be radical in terms of the power relations between media and sources and in forcing both parties to become more accountable to the public, it would work for the greater good. As she writes, "innovative news practices that reveal more about how news is negotiated with sources would promote an empowered, democratized journalism and a more open society” (p. 195).

Lambertus would agree with Peace Journalism's suggestion that, when contacting sources, journalists should attempt to uncover the hidden structures that underlie the appearances of conflict. Lambertus found that those media outlets that used guidelines and conventions concerning the representation of the conflict and the parties involved and those that took into consideration future social relations between these parties were less susceptible to external influences on coverage. "Consequently, they were less likely to engage in inflammatory stereotypical representations” (p. 194).

Lynch (2002) notes that Peace Journalism seeks to involve those individuals who are affected by and must live with the settlement of conflict, rather than the elites who often drive the process of negotiation. It aims to educate audiences to gain a more nuanced understanding of the news, and of "a world consisting of many different perspectives ... [and] many, contingent truths” (p. 4).

18 - Stream: Culture/Politics/Technology 1(2) 


\section{Conclusion}

In this essay, I have argued that through reforming daily journalistic practices, the mass media can position themselves to help solve conflicts between Aboriginal and non-Aboriginal groups in Canadian society, rather than perpetuate them. After discussing some of the characteristic elements of problematic coverage of Aboriginal Canadians, I have tried to show that to improve this coverage, journalists need to reform their daily practice. I have discussed recent research that has identified the ability of journalists and media workers to reform the field of news production, and pointed to Peace Journalism as one emerging field that might provide a blueprint for such action. But for any change to work, the burden of responsibility rests on journalists themselves.

Peace Journalism offers a framework for an engaged, critical journalism that takes responsibility for the consequences of its actions. But with freedom comes responsibility, and if journalists are to argue that they indeed have some measure of agency in their work - that they indeed enjoy limited freedom from structural constraints - they must also work with the responsibility that comes from that freedom. As Lynch (2002) writes, "we need more reporting which opens for inspection the process by which facts are created in order to be reported, and techniques for news to meet the responsibilities this brings” (p. 22).

In this approach, journalists must recognize that they are engaged in the creation of meaning within a field of production, and that for structural change - at either the organizational or the societal level - to take place, they must be involved in reforming daily journalistic practice. As Hackett (2007) writes, journalists must recognize an "ethic of responsibility" and "take into account the foreseeable consequences of [their] behaviour, and adjust it accordingly” (p. 3).

Most journalists enter the field as idealistic individuals; Peace Journalism offers a concrete way to build on that idealism, and at the same time improve coverage in a way that assists, rather than blocks, attempts at reconciliation between Aboriginal and non-Aboriginal Canadians.

\section{Notes}

1. Quoted in The Globe and Mail, British Columbia section, S1, November 24, 2007.

2. In the course of this paper, the terms "Aboriginal," "First Nations," and "Natives" are used interchangeably. 
3. Future study might involve exploring these kinds of decision-making processes in terms of whether their techniques can be applied to journalistic practice.

\section{Author}

Rob McMahon is a doctoral student at the School of Communication, SFU, where he is currently studying journalism practice and intercultural communication with Profs. Robert Hackett and Catherine Murray. He holds a Master of Journalism from the University of British Columbia and a BA in History and Creative Writing from the University of Victoria. His Master's thesis explored the underlying assumptions shaping journalism practice as it related to Aboriginal communities in Canada.

While at UBC, he received the Helen Badenoch Scholarshap and interned at the Prince Rupert Daily News. McMahon also works as a freelance journalist. He regularly contributes to Vancouver's Georgia Straight and the Metro News chain, among other publications. He has also worked with the Federal Treaty Negotiation Office at Indian and Northern Affairs Canada and at the Office of the BC Auditor General.

\section{References}

Alia, V. (1999). Un/Covering the north: News, media and aboriginal people. Vancouver: UBC Press.

Boorstin, D. (1961). The image: A guide to pseudo-events in America. New York: Atheneum.

Bourdieu, P. (2006). On television. In M.G. Durham \& D. Kellner (Eds.), Media and cultural studies: KeyWorks (2nd ed., pp. 328-336). Malden, MA: Blackwell Publishing.

Bredin, M. (1993). Ethnography and communication: Approaches to Aboriginal media. Canadian Journal of Communication, 18(3), 297-313.

Canadian Media Research Consortium. (June, 2004). Report card on Canadian media. Retrieved 10/3, 2007, from http://cmrcccrm.ca/ english/reportcard2004/16.html.

Castells, M. (2000). Materials for an exploratory theory of the network society. The British Journal of Sociology, 52(1), 5-24. 
Dayan, D., \& Katz, E. (1992). Media events: The live broadcasting of history. Cambridge, MA: Harvard University Press.

Gans, H. (1979). Deciding what's news: A study of CBS Evening News, NBC Nightly News, Newsweek, and Time (1st ed.). New York: Vintage Books.

Golding, P., \& Murdock, G. (1996). Culture, communications and political economy. In J. Curran \& M. Gurevich (Eds.), Mass media and society (2nd ed., pp. 11-30). London: Arnold Publishing.

Hackett, R. (2006). Is peace journalism possible? Three frameworks for assessing structure and agency in news media. Conflict \& Communication Online, 5(2), 1-13.

Hackett, R. (May 2007). Journalism versus peace? Notes on a problematic relationship (Basis of presentation for Union of Democratic Communications Conference in October 2007). 1-11.

Harding, R. (2005). The media, aboriginal people and common sense. The Canadian Journal of Native Studies, 25(1), 311-335.

Karim, K. (1993). Constructions, deconstructions and reconstructions: Competing Canadian discourses on ethnocultural terminology. Canadian Journal of Communication, 18(2), 197-218.

Klaidman, S., \& Beauchamp, T.L. (1987). The virtuous journalist. New York: Oxford University Press.

Lambertus, S. (2004). Wartime images, peacetime wounds: The media and the Gustafsen Lake standoff. Toronto: University of Toronto Press.

Leuthold, S. (1996). Representing truth and history in Native American documentary: Indigenous efforts to counter mass stereotypes. Film \& History, 26(1-4), 30-39.

Lynch, J., \& McGoldrick, A. (2005). Peace journalism. Gloucestershire, UK: Hawthorn.

Lynch, J. (2002). Using conflict analysis in reporting: The peace journalism option. Conflict and Peace Forums, 1-32.

Machin, D. (2002). Ethnographic research for media studies. London: Arnold Publishing. 
Minelle, M. (2001). Representing minorities: Canadian media and minority identities. Canadian Ethnic Studies, 33(3), 99-134.

Pedelty, M. (1995). War stories: The culture of foreign correspondents. New York: Routledge.

Peterson, M.A. (2003). Chapter 7: The ethnography of media production. In M.A. Peterson (Ed.), Anthropology \& mass communication: Media and myth in the new millennium (pp. 161-198). New York: Berghahn Books.

Roth, L. (2005). Something new in the air: The story of first peoples television broadcasting in Canada. Montreal \& Kingston: McGillQueen's University Press.

Salter, L. (2005). The communicative structures of journalism and public relations. Journalism, 6(1), 90-106.

Schudson, M. (1978). Discovering the news: A social history of American newspapers. New York: Basic Books.

Schultz, I. (2007). The journalistic gut feeling: Journalistic doxa, news habitus and orthodox news values. Journalism Practice, 1(2), 190-202.

Shoemaker, P., \& Reese, S. (1991). Mediating the message: Theories of influence on mass media content. New York: Longman Publishing.

Singer, B. (1982). Minorities and the media: A content analysis of Native Canadians in the daily press. The Canadian Review of Sociology and Anthropology, 19(3), 348-359.

Ward, S. (2004). The invention of journalism ethics: The path to objectivity and beyond. Montreal \& Kingston: McGill-Queen's University Press.

Webb, J., Schirato, T., \& Danaher, G. (2002). Understanding Bourdieu. London: SAGE Publications. 


\section{A Graduate Journal of Communication}

Stream: Culture/Politics/Technology is a peer-reviewed, open-access e-journal published by the Communication Graduate Student Caucus at Simon Fraser University.

This new journal provides a unique, national forum for emerging Canadian researchers. Encompassing communication studies approaches to the often overlapping "streams" of culture, politics and technology, Stream challenges conceptions of these subjects with innovative, interdisciplinary scholarship.

Visit www.streamjournal.org for more information.

The editors would like to thank and acknowledge the work of all those who volunteered as peer-reviewers for Stream's first volume.

\section{Submit to Stream}

Stream is interested in publishing articles and book reviews by Canadian graduate students in communication studies and related fields. Papers should fit into one of the three proposed "streams," but we invite contributors to challenge their conceptions of these subjects with interdisciplinary approaches to these subject areas. We hope that this student initiative will become a space for graduate students to publish new work and expand upon new ideas, contributing to a thriving graduate intellectual culture.

Visit www.streamjournal.org for full author guidelines and register to submit a paper.

\section{Become a Peer-reviewer}

Register at www.streamjournal.org and enter yourself into our database of graduate student reviewers.

\section{Stream and Creative Commons}

Stream supports and strives to integrate the ideals of the creative commons and copyleft movements at every possible level.

To that end, journal articles are immediately freely available to the public, released under a Creative Commons Attribution-NoncommercialNo derivative works licence.

Furthermore, they may be reproduced and distributed freely for noncommercial uses if the author is identified and nothing is changed.

Consider including Stream articles in your students' courseware packages.

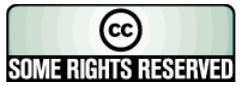

